cerning the rhythm in intermittent hardening and softening and change in color of the cervix, but, I regret to say, I am not able to report on that important feature of the new sign, but hope to present a subsequent paper touching this fact in reporting subsequent observations. I thank Drs. Giffin and Gilbert for their timely observation and description and hope that other physicians will investigate the subject further. I claim that these changes in consistence and color observed in the fundus take place throughout the entire organ, consequently they occur in the cervix uteri and can be recognized on careful investigation.

H. L. E. JoHnson, M.D.

\section{College Credit for Medical Study.}

Chicago, April 27, 1904.

To the Editor:-I note in the letter from Dr. John Rogers, secretary of Cornell University Medical College, in THE JourNAL, April 23, the statement that seven years are required to secure the bachelor's degree and the degree of M.D. May I ask if the Cornell University school now requires all students to take this combined course or if students are still admitted as formerly, with a high-school education, that is, the completion of forty-eight counts in the examinations conducted by the Regents of the State of New York?

Jorrn M. Douson.

[The above was submitted to Dr. Rogers, who replies as follows. - ED.]

New York CrTy, April 30, 1904.

To the Editor:-In reply to the letter of Dr. John M. Dodson, Cornell University Medical College admits students who have had a four years' high-school course, but requires that these students shall include in their preliminary education (and so in the 48 count regents' certificate required by law in New York State), algebra, plane geometry, United States history, two year's of English and two years of Latin, including the first four books of Cosar's Commentaries. A combined course of arts and medicine is optional at present. The number of those who take the combined course is, however, increasing each year in a very gratifying manner.

JOHN ROGERS, JR., Secretary.

\section{Not Professor Forel's Assistant.} Chigur, Swrtzerland, April 6, 1904.

To the Editor:-From August, 1879, until March, 1898, I was the director of the Burghölzh Insane Asylum and profes sor of psychiatry at the University of Zurich, and I desire to make the following statement:

Dr. Carl Bertuhringer, who designates himself a representative of the so-called Koenig Medicine Company of Chicago, and who incidentally represents himself as a former assistant to Professor Forel at the Burghölzh Asylum, was never my assistant and never an assistant at the Burghölzh Asylum. He did, indeed, study medicine in Zurich, and, like other students, studied psychiatry with me, and practiced in the elinic as a so-called practikant, as did other students. Under these circumstances I once permitted him to hypnotize one patient. But he was never either my asylum assistant or my private assistant, and hence has no right to publish himself as such.

Another Dr. Bertuhringer (Dr. Hans Bertuhringer) was actually assistant physician in Burghölzh and is now second physician at the Rheinan Asylum, Canton Zurich. But this is quite another person.

Dr. August Forel.

\section{Queries and Minor Notes.}

Anoxymots Communications will not be noticed. Queries for this column must be accompanied by the writer's name and ad dress, but the request of the writer not to publish his name will be faithfully observed.

\section{THE USE OF ERGOT IN LABOR.}

-., April 15, 1904.

To the Editor:-In your query column I would like to briefly state the following case: Mrs. - - a primipara, began having slight labor pains on Sunday, which recurred at intervals until Wednesday morning, when they came with more regularity and continned suf- ficlently strong and regular to prevent rest throughout the day She slept from 9 p. m., Wednesday, until $1: 30$ a. m., Thursday, when pains again came on with considerable severity and con tinued to come about every 4 to 6 minutes, until $1 \mathrm{p}$. m., when an internal examination was made and dollar-sized dilatation found, the head occupying an L. O. A. position. At $3 \mathrm{p}$. $\mathrm{m}$. the bag of waters broke and the pains became more frequent, but their character made it evident that not much progress was being made. The patient complained constantly and bitterly of continuous pain in the intervals, and had no rest and took no nourishment after $1: 30$ a. $\mathrm{m}$. At $7 \mathrm{p}$. $\mathrm{m}$. another internal examination was made, which showed absolutely the same conditions found at $1 \mathrm{p}$. $\mathrm{m}$. It was then agreed that another physician should be asked to see the case, which was done. After satisfying himself of the conditions he ordered that a dram of ergot be given. At once, in the mind of the younger man, rose visions of three of the greatest teachers of obstetrics in America, all of whom he had heard say repeatedly: "Never, under any circumstances, give ergot until the uterus is empty," and it was with great reluctance that he complied with the older man's orders. Subsequent events, however, set his mind at ease, for inside of a half hour pains were coming regularly at three-minute intervals, were of excellent quality and the patient was resting nicely between pains, often sleeping. At $9 \mathrm{p} . \mathrm{m}$. the baby was born. the placenta following 40 minutes later. It seemed that this one little dose of ergot transformed a tedious, exhausting, non-progressive labor into a perfectly normal one with the happiest results. Was it or was it not good obstetrics?

Young Physician.

AxSWER.-Ergot mould be a valuable aid in obstetric practice to stimulate uterine contractions if it were not dangerous and uncertain. Its characteristic properties have been known for hundreds of years and at times it has been employed extensively. Now most authorities in obstetrics discourage its use because of its dangers. While a proper dose may simply stimulate contractions, increasing their strength and frequency only within safe limits, an excessive dose will cause constant or tetanic contractions. Such contractions, as is well known, are very dangerous to the child, because they shut off the blood supply of the uterus and thus disturb placental circulation and lead to intra-uterine asphyxia. Many still-births can be ascribed to this drig. Moreoper, tetanic contractions of the uterus may lead to its rupture where there is some obstacle to the birth of the child.

It is not easy to specify the proper or safe dose of ergot because of the complicated composition of the drug. During the last twenty years several efforts have been made to determine its active principles, but so far with no agreement on results. Since we have no active principle and since the fluid extract varies in strength one should always use the most reliable preparation he can secure, and if it is used before expulsion of the placenta rather a small dose should be given. Moreover, if the physician contemplates giving ergot to increase labor pains he should assure himself that there is no obstacle to dellvery and that the conditions are such that he can deliver rapidly in case tetanic contractions occur and the child is thereby threatened. After administering the drug he should remain with the patient to care for any emergency that may arise. With these rules of management clearly appreciated ergot may be used by a careful physician without danger and no doubt may be used by a careful physician without danger and no doubt
at times with advantage. At the same time one can understand that the drug should never be used by midwives, and that its careless use by physicians may be productive of great harm.

\section{EQUAL TO LAWSON TAIT OR WILLIAM OSLER.}

A correspondent sends us a copy of the North Brookfield (Mass.) Journal of March 11, 1904, in which appears a letter from a physician concerning the necropsy held on a patient in the presence of another physician, a nurse and a layman. The letter states in preface that "The sickness and death of our much respected citizen, - - has cast a gloom over our townspeople, and has caused many to ask . . . . Could not there have been more done to save his life?" After expressing his regret that time and space do not permit a full and accurate description of the illness and death, the physician says: "I will simply state that the autopsy proved that the diagnosis I made the first day of $\mathrm{Mr}$. - 's illness was correct. Two days later my first diagnosis was verified by Dr. - ... - of - _ - and later was confirmed by Dr. — - of Dr. - informed the family on his arrival that no surgical procedure was then justifiable under the existing conditions, which judgment was proved by the autopsy to have been as reliable and correct as if given by the great Lawson Tait of England. The autopsy showed a large amount of ulceration in the right side where the obstruction occurred; two portions of the small intestines, one about four inches, and one about flve inches in length were in a very much contracted and diseased condition; the appendix showed the result of previous inflammatory conditions, but at this time was intact and in proper condition. The immediate cause of sudden collapse and death in $\mathrm{Mr}$. condition was probably due to an ulceration and perforation of the intestine, which was plainly seen at the autopsy. Therefore, at 